\title{
ISOLATION AND CHARACTERIZATION OF A GLYCOPEPTIDE FROM HUMAN SENESCENT ERYTHROCYTES ${ }^{* * *}$
}

Curtis J. HENRICH ${ }^{\ddagger}$ AND DAVID AMINOFF*

Departments of Internal Medicine, Simpson Research Instutu, and Blological Chemistry, The Universty of Michigan, Ann Arbor, MI 48109 (U.S.A.)

(Received December 20th, 1982; accepted for publication, March 30th, 1983)

\section{ABSTRACT}

A glycopeptide (called "senescence-factor glycopeptide", SF-G) has been isolated from a tryptic digest of human erythrocytes by specific adsorption and elution from immobilized peanut lectin. SF-G was detectable in old but not in young erythrocytes isolated from the same unit of blood. It is present in small quantities, $<1 \%$ of the D-galactose oxidase-borotritide-labeled D-galactosyl residues of erythrocytes. SF-G is free of sialic acid but is quite distinct from a similar glycopeptide isolated from completely desialylated erythrocytes. SF-G binds to spleen monocytes, and this property is abolished upon treatment of SF-G with $\beta$-galactosidase. Some, but not all, of the oligosaccharide chains of the SF-G are of the $O$-glycosyl type, being released by an endo- $N$-acetyl $\alpha$-D-galactosaminidase.

\section{INTRODUCTION}

As erythrocytes age in vivo, they undergo a wide variety of changes, including loss of $10-15 \%$ of the cell-surface sialic acid ${ }^{1,2}$. When sialic acid is removed from mammalian erythrocytes with sialidase, and the cells are reintroduced into the circulation, they are sequestered by the liver and spleen ${ }^{3}$. Furthermore, only $\sim 12 \%$ of the sialic acid needs to be removed in order to see this effect ${ }^{4}$. These observations suggest that the loss of sialic acid may be a significant factor in erythrocyte senescence, and possibly also in their sequestration. Age-dependent (or artificial in vitro) desialylation is accompanied by exposure of D-galactosyl residues, the possible recognition signals by which senescent erythrocytes may be sequestered by reticuloendothelial macrophages. Support for this hypothesis came from results obtained with asialo erythrocytes, which were shown to form rosettes in vitro with liver Kupffer cells and spleen monocytes ${ }^{5}$. This interaction with Kupffer cells was

\footnotetext{
*Dedicated to Professor Elvin A. Kabat.

${ }^{\dagger}$ This study was supported by a grant (HL-AM 17881) from the National Institutes of Health.

${ }^{\ddagger}$ Present address: Michigan Molecular Institute, $1910 \mathrm{~W}$ St. Andrews Rd., Midland, MI 48640.

To whom correspondence should be addressed at Simpson Research Institute, The University of Michigan, Ann Arbor, MI 48109.
} 
shown to be $\beta$-D-galactose specific ${ }^{6-8}$. In vivo sequestration of asialo erythrocytes also could be inhibited by injection of $\beta$-D-galactosyl-containing compound, such as lactose and asialofetuin ${ }^{4}$.

Confirmation of this hypothesis for senescent erythrocytes requires the demonstration of the presence of a D-galactose-containing "senescence factor" and establishment of its biological properties. This paper describes the isolation and biological activities of such a factor unique to human old-erythrocytes.

\section{EXPERIMENTAL}

Materials. All chemicals, unless otherwise noted, were of reagent grade. The density-gradient material, Percoll, was obtained from Pharmacia Fine Chemicals (Uppsala, Sweden), and isotonic "l(0)\%" Percoll was prepared by mixing Percoll ( 9 parts) with 9 sodium chloride ( 1 part). The sources of reagents and brological materials were as follows: DEAE-Sephacel. Sephadex $(j-5)$, and molecularweight protein standards trom Pharmacia; Bio-Gel P-2 from Bio-Rad Laboratories (Richmond. CA); sodium [ ${ }^{5 /} \mathrm{Cr}$ ]chromate from E. R. Squibh and Sons (Princeton $\mathrm{NJ}$ ); sodium boro $\left[{ }^{3} \mathrm{H}\right]$ hydride $(222 \mathrm{mCl} / \mathrm{mmol})$ from New England Nuclear (Boston, MA) (it was stored at $-20^{\circ}$ in $10 \mathrm{~mm}$ sodium hydroxide for a radioactivity of $20 \mathrm{mCi} / \mathrm{mL}$ ); fluorescent microspheres from Covalent Technologies, Inc. (Ann Arbor, MI); immobilized peanut lectin (PNA-agarose) from P-L Biochemicals (Milwaukee, WI); Sprague-Dawley rats from Charles River (Boston, MA); trypsin and D-galactose oxidase (from Dactylium dendroides, EC 1.1.3.9) from Worthington Diagnostic Systems (Frechold. NJ): trypsin unhibitor and NAD from Sigma Chemical Co. (St. Louis, MO); and D-galactose dehydrogenase (EC 1.1.1.48) from Boehringer Mannheim (Indianapolis, IN).

$\beta$-D-Galactosidase (EC 3.2.1.23) was prepared from bovine testes as described by Distler and Jourdian ${ }^{30}$, and endo- $N$-acetyl- $\alpha$-D-galactosaminidase from Clostridium perfringens ${ }^{1 !}$. Sialidase from Vibrio cholerae was prepared and used with tryptic peptides or erythrocytes as described by Aminoff $e^{\prime}$ al. ${ }^{-4}$

The buffered saline solution of isotonic phosphate (PBS) was prepared by dissolving $\mathrm{NaCl}(8.09 \mathrm{~g}) . \mathrm{KCl}(0.29 \mathrm{~g}), \mathrm{KH}_{2} \mathrm{PO}_{4}(0.29 \mathrm{~g})$, and $\mathrm{Na}_{2} \mathrm{HPO}_{4}(1.159 \mathrm{~g})$ in water, adjusting the $\mathrm{pH}$ to the desired value, and diluting to $1 \mathrm{~L}$.

General methods. Human blood from normal, healthy adult males was col lected either into heparinized vacuum tubes or. for large volumes. hy standard blood-bank procedures. All enzymic and chemical reaction involving erythrocytes or tryptic peptides were carried out at a concentration of $5 \times 11^{4}$ crythrocytes (or tryptic peptides from that many cells) per mL. Erythrocytes were counted with a model ZF Coulter Counter (Coulter Electronics. Haleah. FL). The srythrocytes were desialylated as previously described ${ }^{+}$.

Total hexose content was determmed by the anthrone assav ${ }^{2}$ : hexosamine by a modification of the procedure of Elson and Morgan ${ }^{13}$ after acid hydrolysis ( $2 \mathrm{M}$ $\mathrm{HCl}, 2 \mathrm{~h} .100^{\circ}$ ) and neutralization; 2-acetamido-2-deoxyhexose by the Morgan-- 
Elson procedure ${ }^{14}$ with a boiling time of $3 \mathrm{~min}$ in borate; and total sialic acid by the resorcinol assay ${ }^{15}$; and free sialic acid by the thiobarbituric acid assay ${ }^{16}$. Terminal $\beta$-D-galactosyl groups were released from erythrocytes by treatment with 1.0 unit of bovine testes $\beta$-D-galactosidase per $10^{10}$ erythrocytes for $20 \mathrm{~h}$ at pH 4.5 . Free Dgalactose, either after acid hydrolysis (conditions the same as just described) and neutralization or after $\beta$-D-galactosidase treatment, was determined by fluorometric determination of NADH generated in the D-galactose dehydrogenase assay ${ }^{17}$. Protein was determined by the method of Lowry et al. ${ }^{18}$ using bovine serum albu$\min (\mathrm{BSA})$ as standard.

Hydrolyzed carbohydrate material and standard sugars were separated by descending paper chromatography on Whatman 3MM filter paper by development for $18-24 \mathrm{~h}$ in $6: 4: 3(\mathrm{v} / \mathrm{v})$ butanol-pyridine-water. After being dried, the chromatograms were stained by dipping sequentially in $1 \% \mathrm{AgNO}_{3}$ in acetone, $0.5 \mathrm{M} \mathrm{NaOH}$ in ethanol, and $0.2 \mathrm{M}$ sodium thiosulfate in water ${ }^{19}$.

Incorporation of tritium and number of residues labeled. - Labeling of free D-galactose by treatment with D-galactose oxidase and borotritide under the conditions described yielded a valuc of $1.34 \pm 0.09 \times 10^{5} \mathrm{~d}$.p.m./nmol of D-galactose labeled. Appropriate controls were included to correct for acid-stable tritium, tritium incorporated into the reducing end of free D-galactose, and tritium incorporated into the enzyme. This value was used to calculate the number of D-galactosyl groups labeled with tritium in the tryptic peptides.

Separation of old and young erythrocytes. - Percoll was used to separate human erythrocytes according to density. Human blood was layered onto a column of $84 \%$ Percoll-PBS at pH 7.3 and centrifuged at $1200 \mathrm{~g}$ for $10 \mathrm{~min}$. The cell pellet was removed, washed, and used as "old erythrocytes". The top layer was washed

\section{TABLE I}

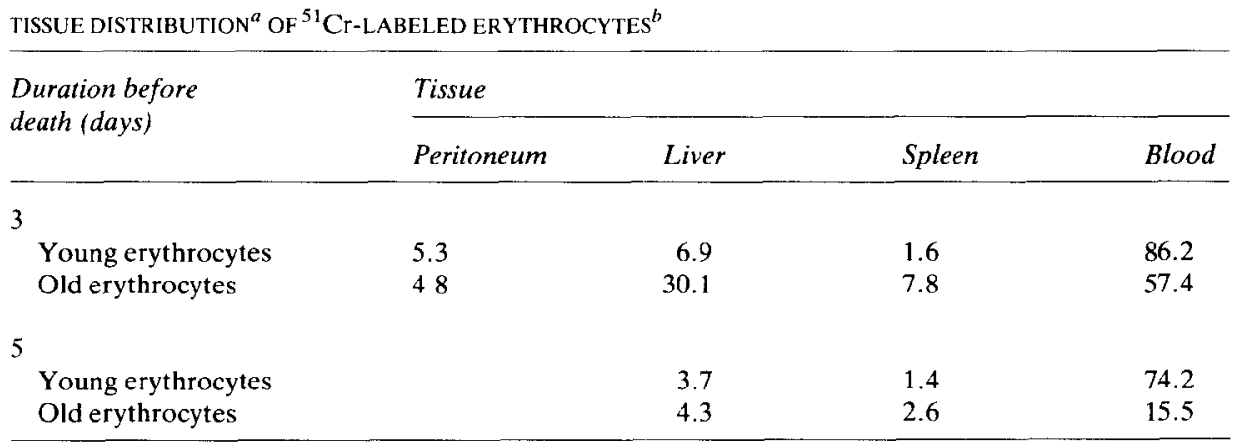

${ }^{a}$ Percent of ${ }^{51} \mathrm{Cr} .{ }^{b}$ The youngest and oldest $5 \%$ of rat erythrocytes were separated with Percoll on the basis of their density. After being washed, the cells were labeled with ${ }^{51} \mathrm{Cr}$ by incubation of $10^{9}$ erythrocytes for $30 \mathrm{~min}$ at $37^{\circ}$ in PBS contaning $20 \mu \mathrm{Ci}$ sodium $\left({ }^{51} \mathrm{Cr}\right)$ chromate, followed by washing to remove excess ${ }^{51} \mathrm{Cr}$. The labeled erythrocytes $\left(5 \times 10^{8}\right)$ were injected into the peritoneum of rats, which were sacrificed 3 or 5 days later for the determination of ${ }^{51} \mathrm{Cr}$ in the peritoneum, liver, spleen, and blood $^{20}$. 
and then centrifuged again in 79-80\% Percoll-PBS; the pellet in this case was regarded as "young erythrocytes". Buffy coat and plasma were separated by centrifugation through $65^{\circ}$. Percoll--PBS.

Age-dependent density separation was confirmed by use of rat erythrocytes. Isolated young and old erythrocytes, each group representing $-5 \mathrm{n}^{\circ}$ of the total. were labeled by incubation with sodium $\left[{ }^{51} \mathrm{Cr}\right]$ chromate and injected into the peritoneum of recipient rats. The distribution of ${ }^{5} \mathrm{Cr}$ was determined in the peritoneum, liver, spleen, and blond ${ }^{20}$ in animals sacrificed after 3 or 5 days (Table I). High-density "old erythrocytes" are cleared from the circulation much more rapidly than are low-density "young erythrocytes", as would be expected if age-dependent separations were achieved. Erythrocytes injected into the peritoneum of a rat have been shown to enter the circulation within $24 \mathrm{~h}$ after injection ".

Preparation of tryptc peptides. - Tryptic peptides were prepared from young and old human erythrocytes by incubation in (1.1\% trypsin in PBS ( $\mathrm{pH} 8.0$ ) for $1 \mathrm{~h}$ at $37^{\circ}$. After addition of trypsin inhibitor, the tryptic peptides were labeled with tritium by D-galactose oxidase-sodium horotritide treatment ${ }^{2 !}$. The condttions used were established to obtain the maximum results from the D-galactose oxidase-dependent tritiation of the whole erythrocytes. Tryptic peptides (from $10^{161}$ erythrocytes) were incubated for $2 \mathrm{~h}$ in the presence of D-galactose oxidase (100) units) in $2 \mathrm{~mL}$ at $\mathrm{pH} 7.0$. and then the solution was boiled for $2 \mathrm{~min}$ to deactrate the D-galactose oxidase and the $\mathrm{pH}$ adjusted to 8.0. After addition of sodium borotritide $(5 \mathrm{mCi})$. the mixture was incubated at room temperature for $30 \mathrm{~min}$. and extracted with $90^{\circ} \mathrm{c}$ phenol. The aqueous phase was dialyzed and the retentate lyophilized ${ }^{22}$.

Isolation of senescence-factor glycopeptide ( $S F-G$ ) on immobilized peanut lectin. - Tryptic $\left[{ }^{3} \mathrm{H}\right]$ peptides were dissolved in PBS $(\mathrm{pH} 7.3)$ and pased through a column ( $5 \mathrm{~mL}$ ) of PNA-agarose. The column was washed with PBS untul no further tritium was detected in the eluate, and the bound material was eluted with PBS $(\mathrm{pH} 7.3)$ containing $0.2 \mathrm{M}$ lactose. The material bound and cluted is subsequently referred to as "senescence-factor glycopeptide" or SF-G.

The same technique was used to prepare SF-G on a large scale Tryptic peptides were prepared from $190 \mathrm{~mL}$ of packed erythrocytes (human type $O$ ) and added to the PNA-agarose column in PBS ( $\mathrm{pH} 7.3$ ). An aliquot of ${ }^{2} \mathrm{H}-\mathrm{SF}-\mathrm{G}$ was included in order to follow binding and elution. After mitial binding and eluton, the column was washed with PBS to remove lactose, and the binding and cluting cycles were repeated twice. The combined eluates were dialyzed to remove lactose and subsequently lyophilized. No ${ }^{3} \mathrm{H}$-labeled material was lost during the dialysis.

Homogeneity of $S F-G$. - Homogeneity of SF- $G$ was investigated by gel filtration and anion-exchange chromatography. Sephadex G-50 gel filtration was performed in a column $(1 \times 45 \mathrm{~cm})$ pre-equilibrated with PBS diluted 101.10 at $4^{c}$. and the elution was carried out with the same buffer at a flow rate of $2 \mathrm{~mL} / \mathrm{h}$. The fractions $(1 \mathrm{~mL})$ were monitored for tritium. DEAE-Sephacel ion-eschange chromatography was performed on a column $(0.5 \times 28 \mathrm{~cm})$ pre-equilibrated at 4 - with 
$10 \mathrm{~mm}$ Tris ( $\mathrm{pH} \mathrm{8.0)}$ ). The sample was prepared in the same buffer and added to the column. After washing with buffer $(8 \mathrm{~mL})$, elution was accomplished with $0-1.0 \mathrm{M}$ $\mathrm{NaCl}$ gradient in the same buffer. Tritium was determined in the fractions $(1 \mathrm{~mL})$.

Biological activity of $S F-G$. - The biological activity of SF-G was investigated by observing the interaction of SF-G covalently bound to fluorescent microspheres with spleen monocytes. SF-G was conjugated to microspheres by mixing SF-G $(2.0 \mu \mathrm{g}$, Lowry protein) with microspheres $(15 \mu \mathrm{L})$ in a total volume of 150 $\mu \mathrm{L}$ of $0.9 \% \mathrm{NaCl}$. This was briefly sonicated and incubated for $18 \mathrm{~h}$ at room temperature. Assay of the supernatant fraction for protein indicated that $49 \%$ of the added SF-G was conjugated to the microspheres. In order to cover all remaining reactive sites on the spheres, the supernatant fraction was removed and the spheres resuspended in $0.9 \% \mathrm{NaCl}$ containing $1 \% \mathrm{BSA}$, sonicated, and incubated overnight at room temperature.

Rat spleen monocytes were prepared as previously described ${ }^{5}$, and suspended in Hank's balanced-salt solution containing 1\% BSA. The interaction with microspheres (SF-G or BSA conjugated) was initiated by mixing $2 \times 10^{6}$ monocytes with a suspension $(15 \mu \mathrm{L})$ of microspheres and centrifuging for $5 \mathrm{~min}$ at $500 \mathrm{~g}$ to enhance contact. After $90 \mathrm{~min}$ at $4^{\circ}$, the pellets were resuspended and observed on a fluorescence microscope. Those cells to which two or more beads were attached were called "positive".

RESULTS

${ }^{3}$ H-Labeling of tryptic peptides. - Tryptic peptides from young and old human erythrocytes were labeled with D-galactose oxidase-sodium borotritide. The results of a duplicate experiment indicate that tritium was incorporated at the level of $1.99 \times 10^{6}{ }^{3} \mathrm{H}$-residues/young erythrocyte, as compared to $2.1 \times 10^{6}$ for old erythrocyte. This represents an age-related increase in susceptibility to D-galactose oxidase of $0.11 \times 10^{6}$ or $5.5 \%$.

Isolation of SF-G by PNA-affinity chromatography. - PNA-agarose affinity chromatography of the tryptic peptides gave the results shown in Fig. 1. Invariably, a component of the glycopeptides was adsorbed on PNA-agarose in the case of old erythrocytes but not young erythrocytes. The mean of several experiments indicated that $0.7 \% \pm 0.5$ of $\left[{ }^{3} \mathrm{H}\right]$ glycopeptides from tryptic digests of young erythrocytes were bound ( 3 experiments), as contrasted to $4.0 \% \pm 1.1$ for old erythrocytes (5 experiments). This corresponds to 1.4 and $8.4 \times 10^{4}{ }^{3} \mathrm{H}$-residues/erythrocyte for young and old erythrocytes, respectively. Thus, an age-related increase of $7.0 \times$ $10^{4} \mathrm{H}$-PNA receptor/erythrocyte, or close to a $500 \%$ increase was observed.

Large-scale preparation of SF-G from cells that were not separated by age gave the results reported in Table II. By the criteria of hexose, hexosamine, and protein content, about $1 \%$ of the total, tryptic-peptide mixture from unfractionated erythrocytes consists of SF-G. 

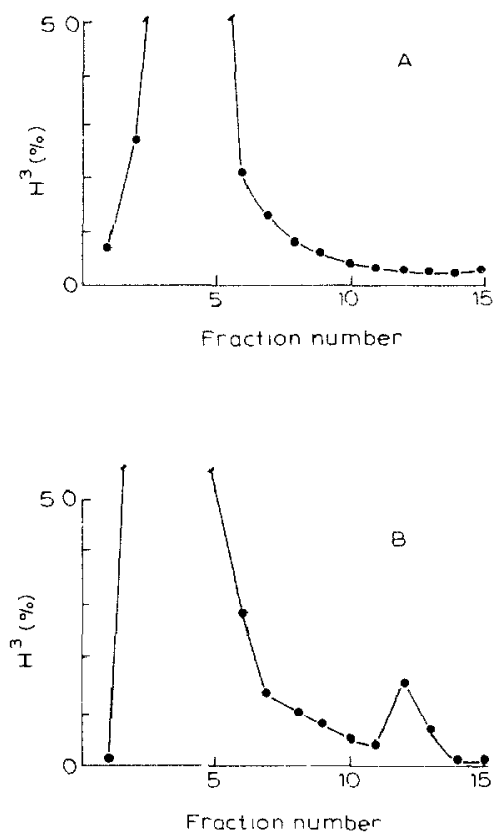

Fig. 1. Affinity chromatography on PNA-agarose of tryptic $\left[{ }^{3} \mathrm{H} /\right.$ peptides. The trypte peptides were prepared and labeled with ${ }^{3} \mathrm{H}$ as described in the Experimental section. Peptides from young $(\mathrm{A})$ and old (B) erythrocytes were added to a column $(5 \mathrm{~mL})$ of PNA-agarose, the column was washed with PBS and then eluted with PBS containing 0.2M lactose (beginning at fraction 9). Fractions (1 mL) were collected and counted for ${ }^{3} \mathrm{H}$ The results are expressed as a percentage of the material applied to the col. umn.

TABLE II

ISOLATION OF SI NESCENCE FACIOR GI YCOPEPTIDF (SF-G) ON A COLUMNOF PVA-AGAROSF ${ }^{\text {t }}$

\begin{tabular}{|c|c|c|c|}
\hline \multirow[t]{2}{*}{ Components } & \multicolumn{3}{|l|}{ Matertal } \\
\hline & $\begin{array}{l}\text { Added to } \\
\text { column } \\
(\mu \mathrm{mol})\end{array}$ & $\begin{array}{l}\text { Eluted } \\
\text { column from } \\
\text { (pmol) }\end{array}$ & $\begin{array}{l}\text { Recovered } \\
\text { as } S F-G \\
(r)\end{array}$ \\
\hline $\begin{array}{l}\text { Hexose } \\
\text { D-Galactose }\end{array}$ & 110 & $\begin{array}{l}0.93 \\
0.49\end{array}$ & 0.85 \\
\hline Hexosamine & 45 & () 45 & 100 \\
\hline Sialic acid & 57 & () & 0 \\
\hline Protein (1n mg) & 30) & 0.39 & 13 \\
\hline
\end{tabular}

"Tryptıc peptıdes, prepared from packed human erythrocytes $(190 \mathrm{~mL})$, were dissolved in PBS (pH 7.3) and passed through a column of PNA-agarose. Bound material was eluted with 0.2M lactose. after which the column was washed with PBS ( $\mathrm{pH} 73$ ), and the unbound peptides recycled through the column two more times. After dialysis to remove lactose, the pooled eluates were ansayed for hexose (anthrone ${ }^{12}$ ), D-galactose (galactose dehydrogenase ${ }^{17}$ after hydrolyss and neutralization), hexosamine ${ }^{17}$ (after hydrolysis and neutratization), 4ialic acid ${ }^{15}$. and protein (Lowry et al ${ }^{1 k}$ ). 
Homogeneity of $S F-G$. - The results of Sephadex G-50 gel filtration and DEAE-Sephacel ion-exchange chromatography of ${ }^{3} \mathrm{H}-\mathrm{SF}-\mathrm{G}$ (see Figs. 2A and 3 ) suggest that the ${ }^{3} \mathrm{H}$-material bound to DEAE-Sephacel at $\mathrm{pH} 8.0$, and eluted by $0.2 \mathrm{M} \mathrm{NaCl}$ represent the principal glycopeptide.

Properties of $S F-G$. - All the ${ }^{3} \mathrm{H}$-label in SF-G was identifiable as a component of D-galactose, of which $22 \%$ was released with bovine testes $\beta$-D-galactosidase. Similarly, $18.3 \pm 2.2 \%$ of the total D-galactose content in nonradioactive SF-G (which accounts for $52.4 \%$ of the total hexose) was released with $\beta$-D-galactosidase. The ratio of galactose to hexosamine was $\sim 1: 1$.

Comparison to tryptic peptides released from asialo erythrocytes. - Tryptic peptides were prepared from asialo erythrocytes, ${ }^{3} \mathrm{H}$-labeled, and subjected to PNA-affinity chromatography, exactly as described earlier. The material eluted from the PNA-agarose column (i.e., asialoglycophorin peptides ${ }^{23,24}$ ) was analyzed (Fig. 2B) in parallel with SF-G, in order to determine whether the two materials were identical. Sephadex G-50 gel filtration gave very similar elution patterns for the two preparations (Fig. 2). Comparison to elution patterns of molecular-weight standards gave estimates of $M_{\mathrm{r}} 19700$ for SF and 24300 for asialoglycophorin tryptic fragment. The distribution of tritium between D-galactose and 2-amino-2deoxy-D-galactose was determined after acid hydrolysis and chromatography on Dowex-50 ion-exchange resin. In SF-G tritium was found to be entirely a component of D-galactose, whereas in asialo erythrocyte peptides $77 \%$ was in D-galactose. $\beta$-D-Galactosidase released $22 \%$ of the tritium from SF-G and $75 \%$ from
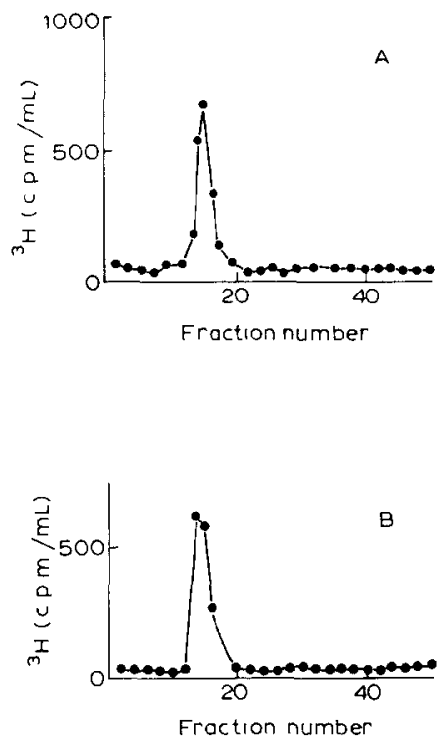

Fig. 2. Gel filtration on Sephadex G-50 of PNA-agarose receptors from old and asialo erythrocytes. The ${ }^{3} \mathrm{H}$-PNA receptors were prepared from tryptic peptides of old (A) and asialo (B) erythrocytes as described in the Experimental section and subjected to gel filtration on a column ( $35 \mathrm{~mL}$ ) of Sephadex $\mathrm{G}$ 50. The effluent was collected in fractions $(1 \mathrm{~mL})$ and assayed for ${ }^{3} \mathrm{H}$. 


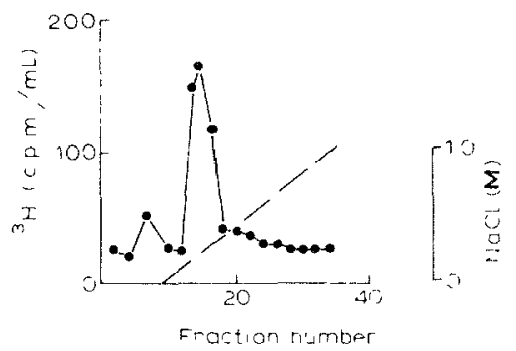

Fig. 3. Chromatography on DEAE-Sephacel of ${ }^{3} \mathrm{H}-\mathrm{SF}-\mathrm{G}{ }^{3} \mathrm{H}-\mathrm{SF}-\mathrm{G}$ was prepared as described in the Experimental section and added to a column $(5.5 \mathrm{~mL})$ of DEAE-Sephacel pre-equilibrated with $10 \mathrm{mu}$ Tris (pH 8.0) and eluted with a $0-1 \mathrm{M}$ gradient of $\mathrm{NaCl}(-\ldots)$ in the same buffer

asialo erythrocyte (this corresponds to $97 \%$ of the $\mathrm{D}-\left[{ }^{3} \mathrm{H}\right]$ galactose). ${ }^{3} \mathrm{H}-\mathrm{SF}-\mathrm{G}$ bound to DF,AE-Sephacel at $\mathrm{pH} 8.0$, whereas the material from asialo erythrocyte did not. Finally, based on the determination of hexose, hexosamine. and protein, SF-G was estimated to contain $\sim 40 \%$ of carbohydrate by weight. and asialo erythrocyte peptides $68 \%$. These results (see Table III) very clearly indicate that SF-C; is not identical to the tryptic fragment of asialo erythrocytes.

Structure of SF-G. - Treatment of SF-G with endo-N-acetyl- $\alpha$-D-galactosaminidase released $15.5 \pm 1.5 \%$ of the total hexosamine content of SF-G as Morgan-Elson positive material. Gel filtration of this digest on Bio-Gel P-2 is shown in Fig. 4. The fractions of the three peaks (Fig. 4) were pooled separately. Calibration of the column gave the following elution volumes: Blue Dextran (void volume), $50 \mathrm{~mL}$; lactose. $92 \mathrm{~mL}$; 2-acetamido-2-deoxy-D-galactose. $96 \mathrm{~mL}$; and Dgalactose. $100 \mathrm{~mL}$. Analysis of the pools is reported in Table IV. As $\beta$-D-galactosidase is a contaminant in the preparation of the endo-galactosaminidase used, the presence of free galactose and 2 acetamido-2 deoxygalactose in equivalent proportions indicates the turther cleavage of the disaccharide released. Paper chromatography of the hydrolyzates of Pools O-1, and O-2, endo-galactosaminidase, and unhydrolyzed Pool O-3 indicates that Pool O-1 contains 2acetamido-2-deoxygalactose. 2-acetamido-2-deoxyglucose. galactose. and man-

TABLE III

COMPARISON OF SF G WITH TRYPTIC PE PTIDE FROM ASIALOERYTHROCYTES

\begin{tabular}{|c|c|c|}
\hline Properties & $S F-G$ & Peptude from astalo ervthrocvte \\
\hline$M_{\mathrm{r}}$ (gel filtration) & 19700 & 24300 \\
\hline Situation of ${ }^{3} \mathrm{H}$ & $100{ }^{r}{ }^{\prime}$ in D)-galactose & $\begin{array}{l}77^{\prime} \text { in un D-galactose } \\
23 \text { in in } 2 \text {-acetamido-2-deoxy-D-galactose }\end{array}$ \\
\hline${ }^{3} \mathrm{H}$ rele ased by $\beta$-I)-galactosidase & $22 \pi$ & $(97 \%$ of $\mathrm{n})-\left[{ }^{3} \mathrm{H}\right]$ galactose $)$ \\
\hline $\begin{array}{l}\text { Bindıng with DEAE-Sephacel } \\
\text { Carbohydrate content } \\
\text { ( }{ }^{r} \text {, by weight) }\end{array}$ & $\begin{array}{l}>00 \% \text { of }{ }^{3} \mathrm{H} \text { at } \mathrm{pH} \times 0 \\
\text { til }\end{array}$ & No binding at pll 80 \\
\hline
\end{tabular}




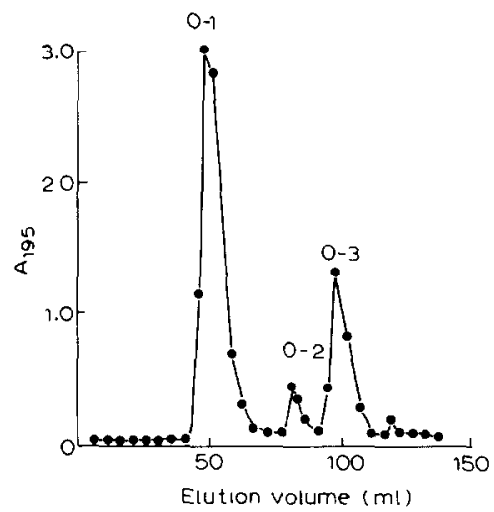

Fig. 4. Gel filtration on Bio-Gel P-2 of the products released from SF-G by endo- $N$-acetyl- $\alpha \cdot \mathrm{D}-\mathrm{galac}-$ tosaminidase. SF-G was prepared and incubated with the enzyme as described in the Experimental section. The incubation mixture was filtered through Bio-Gel P-2 gel and eluted with water. The fractions ( $1 \mathrm{~mL}$ ) were monitored at $195 \mathrm{~nm}$ and pooled as "peaks".

nose, but no fucose; Pool O-2, 2-acetamido-2-deoxygalactose and galactose as a disaccharide; and Pool O-3 free 2-acetamido-2-deoxygalactose and galactose. These results led to the conclusion that the endo-galactosaminidase had released a $\beta$-D$\mathrm{Gal} \rightarrow \mathrm{D}-\mathrm{GalNAc}$ disaccharide (Pool O-2), which was further cleaved by the contaminating $\beta$-D-galactosidase to give free galactose and GalNAc (Pool O-3). This disaccharide is probably the site of the PNA-binding property of SF-G.

\section{TABLE IV}

ANALYTICAL DATA FOR COMPOUNDS OBTAINED BY ACTION OF ENDO- $N$-ACETYL- $\alpha$-D-GALACTOSAMINIDASE ${ }^{a}$ ON SF-G

\begin{tabular}{|c|c|c|c|c|c|c|}
\hline \multirow{2}{*}{$\begin{array}{l}\text { Pool from } \\
\text { column } P-2\end{array}$} & \multicolumn{6}{|c|}{ Sugar component } \\
\hline & $\begin{array}{l}\text { Total } \\
\text { bound } \\
\text { hexose }\end{array}$ & $\begin{array}{l}\text { Total } \\
\text { D-Gal }\end{array}$ & $\begin{array}{l}\text { Free } \\
\text { D-Gald }\end{array}$ & $\begin{array}{l}\beta-\mathrm{D}-G \text { al } \\
\text { released by } \\
\beta \text {-D-galactosidase }\end{array}$ & Hexosamine $f$ & $\begin{array}{l}\text { "Free" } \\
\text { 2-acetamido-2- } \\
\text { deoxygalactose }\end{array}$ \\
\hline O-1 & 77.4 & 53.8 & & 1.4 & & 0 \\
\hline $\mathrm{O}-2$ & 7.1 & 6.4 & & 5.9 & & 6.0 \\
\hline $\mathrm{O}-3$ & 3.7 & 3.7 & 3.4 & & 3.3 & 27 \\
\hline Total & 88.2 & 63.9 & & & & 8.7 \\
\hline Total in SF-G & 93.7 & 67.8 & & 11.3 & 60.0 & 9.3 \\
\hline
\end{tabular}

${ }^{a} \mathrm{nmol} / \mathrm{mL}$ of fraction containing SF-G. ${ }^{b}$ Total bound hexose determined by anthrone ${ }^{12}$. Total D-galactose content was determined by acid hydrolysis $\left(2 \mathrm{M} \mathrm{HCl}, 2 \mathrm{~h}, 100^{\circ}\right)$ neutralızation, and D-galactose dehydrogenase assay ${ }^{17}$. ${ }^{d}$ Free galactose ${ }^{17}$. ${ }^{e} \beta$ - $\mathrm{D}$-Galactosıdase-released $\mathrm{\nu}$-galactose was also determined fluorimetrically ${ }^{17}$. ${ }^{\prime}$ Bound hexosamine was determined as 2 -acetamido-2-deoxygalactose after hydrolysis $\left(2 \mathrm{M} \mathrm{HCl}, 2 \mathrm{~h}, 100^{\circ}\right)$, and assay by Elson-Morgan procedure ${ }^{13}$ g.Free" $N$-acetylhexosamine was determined hy the Morgan-Flson procedure ${ }^{14}$ using 2-acetamido-2-denxygalactose as standard. The disaccharide would also react since the 2 -acetamido-2-deoxygalactose residue is at the reducing end ${ }^{11}$. 
Biological activity of SF-G. - - The SF-G conjugated microspheres exhibited significantly more attachment to rat spleen macrophages $(14.6 \pm 2.0 \%)$ than did BSA-coated microspheres $(2.2 \pm 2.1 \%)$. Treatment of SF-G-microspheres with $\beta$ D-galactosidase reduced the interaction approximately to the level of the interaction of the control BSA $(2.8, c)$, indicating that the biological activity of SF-G (recognition and binding by spleen monocytes) has an absolute requirement for terminal $\beta$-D-galactosyl groups.

DISCLSSION

The results presented herein demonstrate the appearance of a $\beta$-D-galactosecontaining glycopeptide (SF-G) during erythrocyte aging. This is consistent with the hypothesis that sequestration of senescent erythrocytes is mediated by just such a component formed as a result of age-dependent desialylation of a sialylated SF-G precursor.

This work suggests that loss of sialic acid with age is not entirely due to loss of membrane vesicles" 5 . Instead, at least some of the age-related sialic acid loss is specific and accompanied by a transformation resulting in the appearance of SF-G. This is analogous to the mechanism described by Ashwell and Morell ${ }^{26}$ for serum glycoproteins in which the loss of sialic acid, accompanied by exposure of D-galactose residues, is responsible for sequestration. Whereas the two systems thus may be analogous, they are not identical ${ }^{27}$.

Evidence that this senescence-factor glycopeptide is not identical to that isolated from asialo erythrocytes casts doubt on the suitability of asialo erythrocytes for use as a model of erythrocyte senescence. Experiments using asialo trythrocytes $^{1-9}$ were nonetheless responsible for suggesting the presence of an erythrocyte senescence factor. Such a use of asialo erythrocytes has previously been criticized. primarily on the basis that complete desialylation of erythrocytes introduces nonphysiological factors. such as decreased charge-density ${ }^{28.20}$ (which does not appear to change during in vivo aging ${ }^{21}$ ), as well as the possibility of other effects of sialidase (such as adsorption onto erythrocytes ${ }^{2 x}$ ).

Experiments with rats have recently suggested that the asialo erythrocyte is not the ideal model for the study of the mechanism of sequestration of senescent erythrocytes, as aged rat erythrocytes are sequestered both by the liver and spleen of the animal, whereas asialo erythrocytes are taken up by the liver only ${ }^{20}$. We postulated that this difference may result from an indiscriminate desialylation by the bacterial sialidases used, whereas the senescence phenomenon may involve a more discriminating desialylation step that would have resulted in the molecule still containing a sialic acid residue ${ }^{20}$. This postulate has to be revised now since SF-G contains no sialic acid.

The SF-G described herein is interesting because: (a) it possesses the ability to bind to DEAE-Sephacel at pH 8.0, in contrast to the tryptic digest glycopeptides from asialo erythrocyte, which suggests that the points of cleavage of peptides 
with trypsin differ in old and in asialo erythrocyte; (b) it represents but $1-2 \%$ of total glycopeptides released from erythrocyte and asialo erythrocyte, and thus would not be observed under the conditions of isolation generally utilized; (c) it contains no sialic acid; and (d) it contains both $O$-glycosyl- and $N$-glycosyl-linked oligosaccharide chains. D-Galactose was identified in both types of oligosaccharide. The $O$-glycosyl-linked oligosaccharide chains are cleaved off by the endo-galactosaminidase. The total amount of disaccharide released was $10.1 \mathrm{nmol} / \mathrm{mL}$ (see Table IV); this proportion represents the sum of the disaccharide actually released plus the free D-galactose in the hydrolyzate, which is present in equimolar amounts with 2-acetamido-2-deoxy-D-galactose. The D-galactose present in the disaccharide is thus $15.8 \%$ of the total D-galactose in the glycopeptide, the remainder being present in the $N$-glycosyl-linked oligosaccharide chain. Only D-galactose in the disaccharide unit was susceptible to release with $\beta$-D-galactosidase, and it is this D-galactosyl group that is responsible for the biological activity of the molecule.

Recently, others have reported the isolation of "senescent cell antigens" from old erythrocytes based on their interactions with immunoglobulin. Kay ${ }^{31,32}$ has isolated, from senescent erythrocytes, a $62000 M_{\mathrm{r}}$ glycoprotein that binds to a population of $\mathrm{IgG}$ immunoglobulins and inhibits phagocytosis of old erythrocytes in vitro. Lutz ${ }^{33}$ has also isolated an Ig-binding glycoprotein having $M_{\mathrm{r}} 210000$ from old erythrocytes. Very little has been reported to date on the structures of these two materials, but both were reported to contain at least some sialic acid. The senescence-factor glycopeptide described herein may represent a tryptic fragment of these glycoproteins and be looked upon as the active site.

Our results suggest that SF-G is involved in erythrocyte sequestration as a recognition factor. Whether IgG immunoglobulins take part also in this recognition has yet to be established. When SF-G reaches appropriate levels on the old erythrocyte, it may be recognized and bound by reticulo-endothelial macrophages. At this point, the "senescent cell antigens" just mentioned may come into play. For asialo erythrocytes ${ }^{34}$, it has been shown that Ig immunoglobulins are not necessary for binding to macrophages but are probably necessary for phagocytosis.

\section{REFERENCES}

1 A. BaXter and J. G. Beeley, Biochem. Soc. Trans., 3 (1975) 134-136.

2 G. V. F. Seaman. R. J. KNOX. F. J. NordT. AND D. H. Regan. Blood, 50 (1977) 1001-1011.

3 J. Jancik, R. Schauer, And H. J. Streicher, Hoppe-Seyler's Z. Physiol. Chem., 356 (1975) 13291331.

4 D. Aminoff, W. C. Bell, I. Fulton, And N. Ingebrigtsen, Am. J. Hematol., 1 (1976) 419-432.

5 D. Aminoff, W. F. VorderBruegge, W. C. Bell, K. Sarpolis, And R. Williams, Proc Natl. Acad. Scl. U.S.A., 74 (1977) 1521-1524.

6 H. Kolb and V. Kolb-Bachofen, Biochem. Biophys. Res. Commun., 85 (1978) 678-683.

7 H. Kolb, C. Schudt, V. Kolb-Bachofen, ANd H. A. Kolb. Exp. Cell Res., 113 (1978) 319-325.

8 J. SChlepper-Schafer, V. Kolb-Bachofen, and H. Kolb, Biochem J., 186 (1980) 827-831.

9 E. Muller, M. W. Franco, and R. Schauer, Hoppe-Seyler's Z. Physiol. Chem., 362 (1981) 1615 1620 .

10 J. J. Distler and G. W. Jourdian, Methods Enzymol., 50 (1978) 514-520. 
11 C C. Huavg, avd D Aminofr, J. Biol. Chem., 247 (1972) 6737-6742

12 R. DrFy WOOD. Ind Eng. Chem. Anal Ed, $18(1946) 499$.

13 C J M. Rondle and W. T J MORGian. Biochem J, 61 (1955) 586-589

14 J. I. Reissig, J. L. Strominger, and L F. L.t I OIR. J. Biol. Chem, 217 (1955) 959-466

15 I.. Stenverholm, Blochtm. Biophys. Acta, 24 (1957) 604-611

16 D AMINOFF, Biochem J., $81(1961) 384-392$

17 P R. FINCH R YUH. H SolhachtFr ANI) M. A Moscarfilo, Anal Blochem, 31 (1969) $296-$ 305

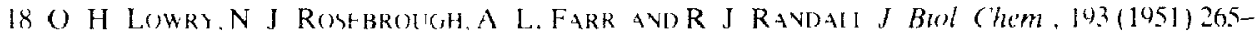
275.

$19 \mathrm{~S}$ M PARIRIDGE, Blochem $J .42(19+8) 238-253$

20) B SMEDSROD AND D AMINOFF, Am $J$ Hematol, (1983) in press.

21 C. G Gahmbergand S. I Hakomori. J. Biol Chem, $248(1973) 4311-4317$

22 G F SPRINGER AND H J YANG, Immunochemustry, 14(1977) 497-502

23 W G. Cartir and N Sharov, Arch Blochem Blophy', 180(1977) 570-572

24 G. H Farrar G UHI FNBrli K AND G Hol 7. Blochim Blophys Acta, 603 (1980) 185-197

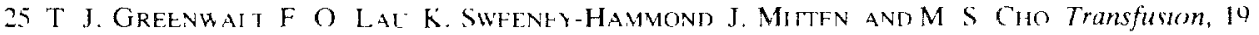
(1979) $n 38-639$

26 (i ASHW'I AVD A G. Morell. Adv. Enzymol, 41 (1974)99-128.

27 D Aminof. W. C Bell, and W F VorderBruggie, in V T. Marchitsi and F Fux(Eds). Cell Surface Carbohydrate \& Biological Recognitton, L iss, New York. 1978, pp 569-581

28 F. J NORDT. R. J KNOX AND G V F. SFEvan.J Cell. Phystol, $97(1978) 209-220$

29 S A. Lavdaw, T. Tevfordf and J. C SChoOley, J Lah Clin Med. 89 (1977) 581-591

$30 \mathrm{~J}$ Darvborough, I. Dunsfori) ayd J A Wallace lor Sung, $17(1969) 241-255$

31 M. M B. KAY. Nature (London), $289(1981) 491-494$

32 M. M B. KaY, Acta Btol. Med Germ., 40(1981) 385-391.

$33 \mathrm{H}$ U LuTZ, Acta Biol Med Germ, 40 (1981) 393-400.

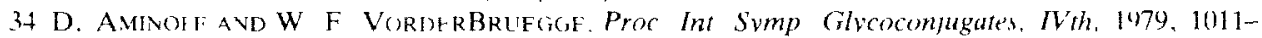
11114 